\title{
Characterization and use of the new NIST rapid pneumatic tube irradiation facility
}

\author{
D. A. Becker* \\ Nuclear Methods Group, Analytical Chemistry Division/CSTL, National Institute of Standards and Technology, \\ Gaithersburg, MD 20899_0001, USA
}

(Received February 5, 1998)

\begin{abstract}
Recently a new rapid pneumatic tube facility was inserted into a long unused location in the NIST 20 MW nuclear reactor. This facility was designed and constructed specifically for rapid INAA using short lived activation products. Included is a computer controlled console which uses fast sensors to accurately measure the irradiation capsule flight time, and a loss-free counting system connected to a $32 \%$ efficient HPGe detector with a transistor reset preamplifier. Measurement of travel times from end-of-irradiation to detector were $473 \pm 8 \mathrm{~ms}$. Measurement of the thermal neutron fluence rate was $5.0 \cdot 10^{13} \mathrm{n} \cdot \mathrm{cm}^{-2} \cdot \mathrm{s}^{-1}$. The other three pneumatic tubes in the NIST reactor have transfer times of 3 to 15 seconds, and no timing capability more accurate than human response. This new facility substantially improves our ability to accurately determine activation products with half-lives from 1 to 100 seconds. Characterization information reported on this new irradiation facility includes absolute fluence measurements, fluence rate variations within the capsule and variations with time, and determination of analytical sensitivities for fluorine-20, selenium- $77 \mathrm{~m}$, and silver- $110 \mathrm{~g}$.
\end{abstract}

\section{Introduction*}

There are a number of elements which upon neutron irradiation produce very short-lived activation products, which are potentially useful for determination by instrumental neutron activation analysis (INAA) (Table 1). In some cases these nuclides may be the only available activation product (e.g., F, O, and $\mathrm{Pb}$ ); in other cases the nuclides are activation products which provide improved sensitivity, accuracy, or ease of determination (e.g., Se, $\mathrm{Ag}, \mathrm{Rh}, \mathrm{Cu}$ ). In all cases the short analysis completion times are a distinct advantage. In addition, at NIST much of the effort of the Nuclear Methods Group is in the analysis and certification of reference materials. Since it has been demonstrated that all analytical techniques which require dissolution of the sample before analysis are subject to errors due to incomplete dissolution or recovery, ${ }^{1}$ INAA has been effectively utilized for evaluating and eliminating potential analytical errors due to these problems. Therefore, the identification of additional elements that can be quantitatively determined nondestructively with high accuracy and sensitivity is of substantial benefit to NIST.

The NIST nuclear reactor (NBSR) is a $20 \mathrm{MW}$ research reactor, first operated in 1967 . It reached 10 MW power operation in 1969 , and was upgraded to 20 $\mathrm{MW}$ in 1985. It is cooled and moderated with $\mathrm{D}_{2} \mathrm{O}$, and has a split core designed for the generation of highly thermalized neutron beams for materials research purposes. In 1990 the NBSR experimental beam facilities expanded to include a cold neutron facility.

While over the years the primary use of the NBSR has been for research using neutron beams, the reactor

*E-mail: donald.becker@nist.gov

0236-5731/98/USD 17.00

(C) 1998 Akadémiai Kiadó, Budapest

All rights reserved design which produced highly thermalized neutrons has also been extremely beneficial for use by neutron activation analysis (NAA). There are several pneumatic tube irradiation facilities, covering a range of neutron fluences and neutron energy spectra. All of these pneumatic tubes use the same large, but relatively slow moving irradiation capsules ("rabbits") with a $40 \mathrm{ml}$ capacity.

The recent extended shutdown of the NIST reactor for modifications and facilities upgrade provided the opportunity to obtain a new pneumatic tube irradiation facility and insert it into the reactor at a previously used thimble location (RT-2). The irradiation terminal and the send/receive portions of this new facility were constructed by contractors to our design requirements, specifically for rapid INAA using short-lived activation products. Included in this new RT-2 facility is a computer control console used to send the irradiation capsules ("rabbits") with a preset irradiation time, count, and return them to a shielded storage facility. The system also has a 20 sample automatic loader, and a number of fast infrared and acoustic sensors to accurately measure the "rabbit" flight time from end-ofirradiation (i.e., out-of-reactor) to the detector (i.e., the decay time). The irradiation capsules for this new system are considerably smaller than the other existing tubes ( $1.4 \mathrm{ml}$ capacity), both for speed and for a smaller total capsule analytical blank, since the samples will be counted while still inside the irradiation facility (at least initially). The facility also includes a loss-free counting system connected to a $32 \%$ efficient HPGe detector with a fast transistor reset preamplifier. This RT-2 system design and construction has been reported elsewhere and thus will not be described in detail here. ${ }^{2,3}$ This paper will report on the facility operational and irradiation characteristics which affect their use for high accuracy 
Table 1. Selected short half-life activation products

\begin{tabular}{|c|c|c|c|c|c|c|c|}
\hline Element & Nuclide & $T_{1 / 2}, \mathrm{~s}$ & Abund., $\%$ & $\sigma, \mathbf{b}$ & $E_{\gamma}, \mathrm{keV}$ & BR, \% & $\gamma / \mathrm{s} / \mu \mathrm{g}^{\mathrm{a}}$ \\
\hline Chlorine & ${ }^{38 \mathrm{~m}} \mathrm{Cl}$ & 0.715 & 24.23 & 0.005 & 671.3 & 100 & 630 \\
\hline Lead & ${ }^{207 \mathrm{~m}} \mathrm{~Pb}$ & 0.80 & 24.1 & 0.03 & 1064 & 88.6 & 530 \\
\hline Indium & ${ }^{116 \mathrm{~m} 2} \mathrm{In}$ & 2.16 & 95.72 & 87 & 162.4 & 50 & $3.1 \cdot 10^{6}$ \\
\hline Erbium & ${ }^{167 \mathrm{~m}} \mathrm{Er}$ & 2.27 & 33.6 & 15 & 207.8 & 43 & $1.0 \cdot 10^{5}$ \\
\hline Fluorine & ${ }^{20} \mathrm{~F}$ & 11.0 & 100 & 0.0096 & 1633.6 & 100 & 930 \\
\hline Indium & ${ }^{116 g} \mathrm{In}$ & 14.2 & 95.72 & 45 & 1293 & 1.2 & 820 \\
\hline Selenium & ${ }^{77} \mathrm{~m} \mathrm{Se}$ & 17.4 & 9.1 & 21 & 161.9 & 59.5 & 16900 \\
\hline Scandium & ${ }^{46 \mathrm{~m}} \mathrm{Sc}$ & 18.7 & 100 & 10 & 142.5 & 100 & $2.43 \cdot 10^{5}$ \\
\hline Hafnium & ${ }^{179 m} \mathrm{Hf}$ & 18.7 & 27.3 & 50 & 214.3 & 82 & $1.0 \cdot 10^{5}$ \\
\hline Silver & ${ }^{110 \mathrm{~g}} \mathrm{Ag}$ & 24.6 & 48.17 & 87 & 657.7 & 4.5 & 18700 \\
\hline Oxygen & ${ }^{19} \mathrm{O}$ & 26.9 & 0.20 & 0.00016 & 1357 & 59 & 10300 \\
\hline Rhodium & ${ }^{104 \mathrm{~g}} \mathrm{Rh}$ & 42.3 & 100 & 134 & 555.8 & 2 & 1550 \\
\hline Dysprosium & ${ }^{165 m}$ Dy & 76.36 & 28.2 & 1700 & 516 & 11.7 & 96000 \\
\hline Aluminum & ${ }^{28} \mathrm{Al}$ & 135 & 100 & 0.233 & 1779 & 100 & 1370 \\
\hline Vanadium & ${ }^{52} \mathrm{~V}$ & 226 & 99.75 & 4.91 & 1434 & 100 & 9000 \\
\hline Rhodium & ${ }^{104 m} \mathrm{Rh}$ & 262 & 100 & 11 & 51.4 & 57 & 10300 \\
\hline Copper & ${ }^{66} \mathrm{Cu}$ & 306 & 30.83 & 2.17 & 1039 & 9 & 67 \\
\hline Titanium & ${ }^{51} \mathrm{Ti}$ & 345.6 & 5.4 & 0.177 & 320.1 & 95 & 17 \\
\hline Calcium & ${ }^{49} \mathrm{Ca}$ & 523.2 & 0.187 & 1.1 & 3084.3 & 91.7 & 2.0 \\
\hline Magnesium & ${ }^{27} \mathrm{Mg}$ & 567 & 11.01 & 0.036 & 1014.4 & 28.6 & 1.8 \\
\hline Cobalt & ${ }^{60 \mathrm{~m}} \mathrm{Co}$ & 630 & 100 & 20 & 58.6 & 2.1 & 250 \\
\hline Iodine & ${ }^{128} \mathrm{I}$ & 1500 & 100 & 6.2 & 442.9 & 17.5 & 120 \\
\hline Indium & ${ }^{116 \mathrm{~m} 1} \mathrm{In}$ & 2353 & 95.72 & 75 & 1097 & 53 & 3400 \\
\hline Barium & ${ }^{139} \mathrm{Ba}$ & 5026 & 71.7 & 0.45 & 165.9 & 22.6 & 1.8 \\
\hline
\end{tabular}

${ }^{a}$ Calculated for $1 \mathrm{~s}$ irradiation at a thermal neutron fluence rate of $5 \cdot 10^{13} \mathrm{n} \mathrm{cm}^{-2} \cdot \mathrm{s}^{-1}$ for $1 \mu \mathrm{g}$ of the element

INAA, and the methods used to obtain these data. The characterization effort described is an extension of work performed previously on existing NIST pneumatic tubes, ${ }^{4-6}$ and these parameters must be fully understood before high accuracy INAA determinations can be made reliably.

\section{Experimental}

The characteristics to be evaluated include timing measurements, absolute fluence rate determinations for thermal and fast neutrons, neutron variations within the irradiation capsule volume, and sensitivity determinations for several representative elements. For these measurements the system was operated at $310 \mathrm{kPa}$ (45 pounds $\left./ \mathrm{in}^{2}\right) \mathrm{CO}_{2}$ pressure for the send station, and $240 \mathrm{kPa}$ ( 35 pounds $/ \mathrm{in}^{2}$ ) $\mathrm{CO}_{2}$ pressure for return of the rabbit to the detector and later to the dump station. The higher pressure for the send station was found to be necessary for reliable operation of the diverter valves. The return pressure was kept at the lower pressure in order to minimize shock to the polyethylene rabbits hitting the detector station. Under these conditions, it is estimated that the rabbit for this facility is traveling at a rate of approximately 20 meters per second. These operational conditions are variable and may be changed at a later date if it is found to be advantageous to do so.

\section{Timing measurements}

The timing measurements made included both the reproducibility of return time from the irradiation position to the detector, and the absolute time accuracy for variable irradiation times. The return times were recorded at the computer via a signal from the fast solenoid providing the return gas (START of return time) and from the infrared sensor at the detector station recording the arrival of the rabbit (END of return time). The variability of these times indicates the reproducibility of the return times. The value obtained was for a series of 27 irradiations made over a three day period.

The absolute time accuracy measurements for the time of irradiation was determined by a series of irradiations ranging from 1 to 60 seconds, completed within a period of 20 minutes. The reactor power was held constant during this period. Each rabbit had an accurately weighted copper foil fluence monitor inside, firmly held in a fixed, reproducible position. After all irradiations were completed, the copper foils were removed from the rabbits and, after decay of the 5.1-min ${ }^{66} \mathrm{Cu}$ activity, were counted in a reproducible geometry on a HPGe detector. The $511 \mathrm{keV}$ positron activity of ${ }^{64} \mathrm{Cu}$ was determined for each foil, and the relative activities per second of irradiation compared. For all 
copper foils, a metal disk was placed on top of the foil during counting, to assure that all positrons were annihilated in close proximity to the foil itself.

\section{Absolute fluence rate measurements}

The absolute fluence rates for thermal neutrons were measured in RT-1 and 4 as well as RT-2, in order to reconfirm previous measurements for these two existing pneumatic tubes, and the fluence rates for these three irradiation positions compared. Measurements were made using cobalt and copper, using their well known thermal neutron $(\mathrm{n}, \gamma)$ reactions forming the activation products ${ }^{60} \mathrm{Co}$ and ${ }^{64} \mathrm{Cu}$. The cobalt is a known component of the iron foils actually irradiated, and is a minor constituent of the iron foil at a concentration of $0.138 \pm 0.005 \%$ by weight. This eliminates the problem of neutron self-shielding in pure cobalt foils. Nickel foils were used for measurement of the fast neutrons present in these facilities, with determination of the ${ }^{58} \mathrm{Co}$ activation product from the $(n, p)$ nuclear reaction. For the nickel, an activation cross section of $420 \mathrm{mb}$ was used to provide the integral fast neutron fluence rate above $2.9 \mathrm{MeV} .^{5}$

Irradiation of iron and nickel foils were made in three pneumatic tubes (RT-1, RT-2 and RT-4) for 15 minutes each, all virtually simultaneously. Irradiation of copper foils in RT-2 and RT-4 were made separately, for one minute and two minutes, respectively. The HPGe detector used to count all foils were calibrated for absolute detection efficiencies at each counting geometry using NIST mixed radionuclide SRMs.

\section{Neutron variations within the rabbit}

Previous measurements in the existing NIST pneumatic tube facilities had demonstrated that the side-to-side variations in the large rabbits were below measurement uncertainties $(<0.1 \%$ relative), while the end-to-end variations ranged from $10 \%$ to $40 \%$, but were linear. ${ }^{46}$ To evaluate variations in the new RT-2 facility, a series of iron foils were placed at the top, bottom, and vertically through the middle of the small rabbit. The rabbit was then irradiated for $10 \mathrm{~min}$, and after a few days decay the foils were removed, cut into portions, and counted on a calibrated detector.

\section{Elemental sensitivities}

In order to measure the sensitivity of several elements in RT-2 and compare the results with the calculated values found in Table 1, known amounts of $\mathrm{Se}, \mathrm{Ag}$, and F from NIST Spectrometric Solution SRMs were deposited onto small disks of cellulose filter paper and allowed to dry under clean conditions. These disks were then encapsulated in the small RT-2 rabbits and irradiated for $1 \mathrm{~s}$ ( $10 \mathrm{~s}$ for fluorine), returned to the 
detector station, and counted for $60 \mathrm{~s}$ on the system detector after a $4 \mathrm{~s}$ decay. Elemental sensitivities were then calculated as counts/ $\mu \mathrm{g}$ element for the irradiation, and estimated elemental detection limits for an interference free determination also calculated.

\section{Results and discussion}

\section{Timing measurements}

The results for measurements made to measure the timing reproducibility averaged $473 \pm 8 \mathrm{~ms}$ for 27 runs over the three days. However, it should be noted that this is the time from end-of-irradiation to in-detector only;

it does not include the time required to start the detector after it receives the start signal. At present the loss-free counting system has not been electronically connected to the irradiation control computer, and thus the detector start time was initiated manually for these measurements.

Results for absolute time accuracy measurements vs. time of irradiation are found in Fig. 1. As can be seen from this figure the radioactivity per second due to the first second of an irradiation is 23\% larger than the average irradiation over a longer time period. In fact, the longer irradiation time for the first second is very close to accounting for all of the deviation from a relative fluence rate of 1.00 for all irradiation times, if

Table 2. Results from thermal and fast neutron fluence rate measurements

\begin{tabular}{lcccc}
\hline \multicolumn{2}{c}{ Thermal fluence rate } & \multicolumn{3}{c}{ Integral fast fluence rate } \\
P-tube & Element & Thermal fluence rate, $\mathrm{n} \cdot \mathrm{cm}^{-2} \cdot \mathrm{s}^{-1}$ & Reaction & Fast fluence rate, $\mathbf{n} \cdot \mathrm{cm}^{-2} \cdot \mathrm{s}^{-1}$ \\
\hline RT-1 & Cobalt & $10.5 \cdot 10^{13}$ & ${ }^{58} \mathrm{Ni}(\mathrm{n}, \mathrm{p})^{58} \mathrm{Co}$ & $15.7 \cdot 10^{10}$ \\
RT -2 & Cobalt & $5.0 \cdot 10^{13}$ & $58 \mathrm{Ni}(\mathrm{n}, \mathrm{p})^{58} \mathrm{Co}$ & $2.7 \cdot 10^{10}$ \\
RT -2 & Copper & $5.1 \cdot 10^{13}$ & - & - \\
RT -4 & Cobalt & $3.5 \cdot 10^{13}$ & $58 \mathrm{Ni}(\mathrm{n}, \mathrm{p})^{58} \mathrm{Co}$ & $1.2 \cdot 10^{10}$ \\
RT -4 & Copper & $3.3 \cdot 10^{13}$ & - & - \\
\hline
\end{tabular}

Note: Integral fast neutron fluence rate for the ${ }^{58} \mathrm{Ni}(\mathrm{n}, \mathrm{p})^{58} \mathrm{Co}$ nuclear reaction used includes all neutrons above $2.9 \mathrm{MeV}$ in energy

\section{Absolute fluence rate measurements}

The results for absolute fluence rate measurements are found in Table 2. This table includes data obtained for both the thermal and fast neutrons. Agreement between the cobalt and copper thermal data is excellent. The thermal neutron fluence rate for RT-2 was found to

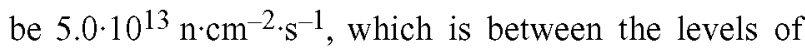
the other two main pneumatic tube facilities at this reactor.

The integral fast neutron fluence rate for RT-2 is $2.7 \cdot 10^{10} \mathrm{n} \cdot \mathrm{cm}^{-2} \cdot \mathrm{s}^{-1}$ for all neutrons above $2.9 \mathrm{MeV}$ in energy, made using the ${ }^{58} \mathrm{Ni}(\mathrm{n}, \mathrm{p}){ }^{58} \mathrm{Co}$ nuclear reaction. The value obtained for RT-4 using an identical the first second is excluded. For example, for a three second irradiation, the first second at 1.23 plus two additional seconds at 1.00 would provide an average relative fluence rate of 1.077 , very close to the observed value of 1.075 . This large deviation for the first second is due either to a system delay in starting the irradiation timer or, more likely, a $0.23 \mathrm{~s}$ delay in ejecting the rabbit once the "end irradiation" signal is received. This timing problem may be able to be adjusted electronically. However, it is only a problem for analytical measurements if the irradiation times are not kept constant between all samples, standards, and control materials.

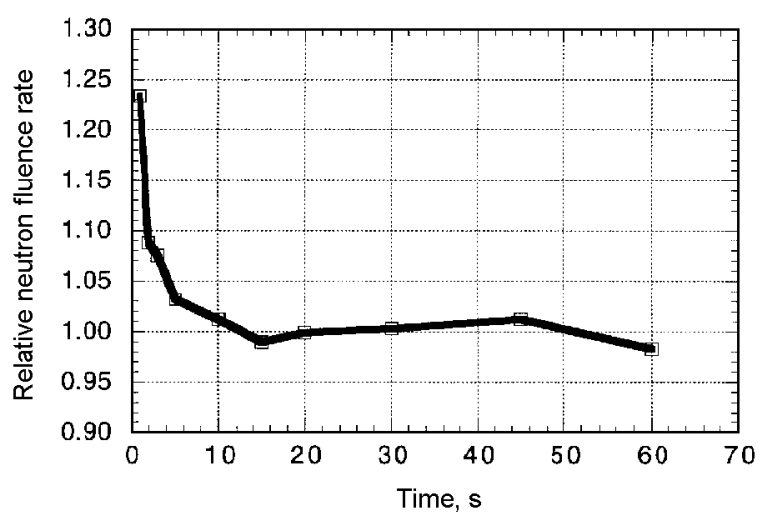

Fig. 1. Copper foil activation as a function of irradiation time 


\section{Neutron variations within the rabbit}

Results from iron foils used to measure the neutron variations within the irradiation capsule can be seen in Fig. 2. This figure shows the fluence rate as a function of distance from the bottom of the capsule (i.e., end closest to the reactor center line for the horizontal capsule position). Over the $19 \mathrm{~mm}$ length of the rabbit interior, the neutron drop off is $9.6 \%$. The top and bottom foils are fixed, and so represent known locations. Based on what is known from the other NBSR horizontal pneumatic tube irradiation facilities, the drop off is expected to be linear. The data in Figure 2 shows a slight deviation from linearity, up to a maximum of about $1 \%$. This deviation is most likely due to movement of the middle foil positions as a result of the very high travel speeds of this small rabbit and the resulting sharp impact upon reaching the irradiation terminal. These measurements will be further evaluated to either confirm or correct the deviations from linearity.

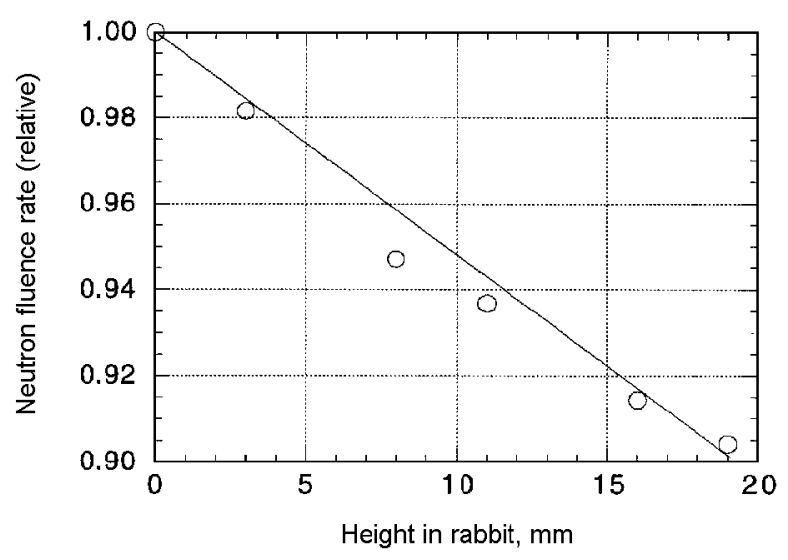

Fig. 2. Neutron fluence rate drop-off relative to height in the RT-2 rabbit

Table 3. Results from the experimental determination of elemental sensitivities in RT-2

\begin{tabular}{lccc}
\hline Element & Half-life, $\mathrm{s}$ & $\mathrm{C} / \mathrm{s} / \mu^{\mathrm{a}}$ & Est. sensitivity, ${ }^{\mathrm{b}} \mu \mathrm{g}$ \\
\hline Selenium & 17.4 & 11.4 & 0.05 \\
Silver & 24.6 & 3.1 & 0.2 \\
Fluorine & 11.0 & 0.11 & 5 \\
\hline
\end{tabular}

${ }^{\text {a }}$ Counts per microgram of element per second live time of the count ( 1 $\mathrm{s}$ irradiation; $4 \mathrm{~s}$ decay, $60 \mathrm{~s}$ count at approximately $20 \mathrm{~cm}$ away from the detector).

${ }^{\mathrm{b}}$ For irradiation times of $15 \mathrm{~s}$ for $\mathrm{Se}, 25 \mathrm{~s}$ for $\mathrm{Ag}$, and $10 \mathrm{~s}$ for $\mathrm{F}$; detection limit was variable based on background levels.

\section{Elemental sensitivities}

Finally, measurement of experimental elemental sensitivities was made for the elements $\mathrm{Se}, \mathrm{Ag}$, and $\mathrm{F}$.
The results for these measurements are found in Table 3. These data confirm the calculations in Table 1 as providing $\mu \mathrm{g} / \mathrm{g}$ level sensitivities for these elements. The spectra obtained also confirm that irradiations of 1 to $25 \mathrm{~s}$ coupled with counts of one to two min will provide adequate analytical sensitivities for rapid determination in a variety of matrices. 
In situations where increased sensitivities are required, the sample to detector distance could be decreased if the induced matrix radioactivity were relatively low. However, for general usage, it has been found that the $20 \mathrm{~cm}$ distance used permits adequate sensitivity while limiting the interference of background radiation due to the matrix and/or the irradiation capsule.

\section{Conclusions}

The data obtained on the new RT-2 rapid pneumatic tube irradiation and analysis system shows it to be a useful addition to the NAA facilities at the NBSR. In particular, the very rapid transfer of the samples from the reactor to the counting station will allow use of a number of activation products for use in our studies that were not previously available to us.
Contribution of the National Institute of Standards and Technology, not subject to copyright.

\section{References}

1. R. R. GreenberG, H. M. Kingston, R. L. Watters, JR., K. W. PRatt, Fresenius J. Anal. Chem., 338, (1990) 394.

2. D. A. BeCKeR, R. M. Lindstrom, J. K. LANGland, R. R. GREENBERG, J. Trace Microprobe Tech., 14 (1996) No. $1,1$.

3. R. M. Lindstrom, D. A. Becker, J. K. LANGLAND, R. R. GREENBERG, J. Radioanal. Nucl. Chem., 215 (1997) 47.

4. D. A. BECKER, NBS Tech. Note 548, U.S. Dept. Commerce, 6-23 (1970).

5. D. A. Becker, P. D. Lafleur, J. Radioanal. Chem., 19 (1974) 149.

6. D. A. BECKER, J. Radioanal. Chem., 110 (1987) 393.

7. W. N. McElroy, L. S. Kellogg, W. Y. Matsumoto, J. L. JACKSON, Hanford Engineering Development Laboratory, Monthly Progress Report, U.S. Atomic Energy Commission, Washington, DC, Oct. 1972, p. 1. 